\title{
Pollution Characteristics and Possible Sources of Seldom Monitored Trace Elements in Surface Sediments Collected from Three Gorges Reservoir, China
}

\author{
Bo Gao, ${ }^{1,2}$ Xin Wei, ${ }^{3}$ Huaidong Zhou, ${ }^{1,2}$ Jin Lu, ${ }^{2}$ Hong Hao, ${ }^{2}$ and Xiaohong Wan ${ }^{2}$ \\ ${ }^{1}$ State Key Laboratory of Simulation and Regulation of Water Cycle in River Basin, China Institute of Water Resources \\ and Hydropower Research, Beijing 100038, China \\ ${ }^{2}$ Department of Water Environment, China Institute of Water Resources and Hydropower Research, Beijing 100038, China \\ ${ }^{3}$ State Key Laboratory of Water Environment Simulation, School of Environment, Beijing Normal University, Beijing 100875, China
}

Correspondence should be addressed to Bo Gao; gaosky34@hotmail.com and Huaidong Zhou; hdzhou@iwhr.com

Received 25 April 2014; Accepted 25 June 2014; Published 17 July 2014

Academic Editor: Georgiy B. Shul'pin

Copyright (C) 2014 Bo Gao et al. This is an open access article distributed under the Creative Commons Attribution License, which permits unrestricted use, distribution, and reproduction in any medium, provided the original work is properly cited.

\begin{abstract}
A geochemical study of Three Gorges Reservoir (TGR) sediments was carried out to analyze the concentrations, distribution, accumulation, and potential sources of the seldom monitored trace elements (SMTEs). The mean concentrations of Li, B, Be, Bi, V, $\mathrm{Co}, \mathrm{Ga}, \mathrm{Sn}, \mathrm{Sb}$, and Tl were 47.08, 2.47, 59.15, 0.50, 119.20, 17.83, 30.31, 3.25, 4.14, and $0.58 \mathrm{mg} / \mathrm{kg}$, respectively. The concentrations of total SMTEs, together with their spatial distribution, showed that the SMTEs were mainly due to anthropogenic inputs in the region of TGR. The assessment by Geoaccumulation Index indicates that $\mathrm{Tl}, \mathrm{Be}, \mathrm{V}, \mathrm{Co}$, and $\mathrm{Fe}$ are at the unpolluted level; $\mathrm{Bi}$, $\mathrm{Li}$, $\mathrm{Ga}$, and $\mathrm{Sn}$ were at the "uncontaminated to moderately contaminated" level. However, B was classified as "moderately contaminated" level and $\mathrm{Sb}$ was ranked as "strongly contaminated" level. The pollution level of the SMTEs is $\mathrm{Sb}>\mathrm{B}>\mathrm{Bi}>\mathrm{Li}>\mathrm{Ga}>\mathrm{Sn}>\mathrm{Tl}>\mathrm{Be}>\mathrm{V}>\mathrm{Co}$ $>$ Fe. The results of Correlation Analysis and Principal Component Analysis indicated Be, V, Co, Ga, Sn, Tl, Bi, and Fe in sediments have a natural source. B and Li were positively correlated with each other and mainly attributed into similar anthropogenic input. In addition, $\mathrm{Sb}$ has less relationship with other SMTEs, indicating that $\mathrm{Sb}$ has another kind of anthropogenic source.
\end{abstract}

\section{Introduction}

River sediment is both the source and sink of the heavy metals in water environment. It is also one of the most important media in water environment to assess the contamination level of aquatic ecosystems [1]. Up to now, the concentrations, accumulation, spatial distributions, sources, and ecological assessment of heavy metal pollution resulting from commonly monitored trace elements (i.e., As, $\mathrm{Cd}, \mathrm{Cr}, \mathrm{Cu}, \mathrm{Pb}$, and $\mathrm{Hg}$ ) in river sediments have been deeply investigated [2, 3]. However, increasing industrial use of seldom monitored trace elements (SMTEs: Li, B, Be, Bi, V, Co, Ga, Sn, Sb, and $\mathrm{Tl}$ ) would in theory lead to increased environmental concentrations. In addition, because of their bioavailability, toxicity, persistence, and nondegradability in the environment [4-10], SMTEs should be of global interest and be much accounted for; but there is little information on geochemical behaviors of SMTEs in river sediments. The knowledge of the concentrations, distributions, and enrichment of SMTEs in sediments plays a key role in tracing SMTEs sources and assessing the potential ecological risks of SMTEs in aquatic systems $[7,11]$.

The TGR area is located in China at west of Hubei Province and middle east of Chongqing city $\left(28^{\circ} 32^{\prime}-31^{\circ} 44^{\prime} \mathrm{N}\right.$ and $105^{\circ} 44^{\prime}-111^{\circ} 39^{\prime} \mathrm{E}$ ), covering an overall area of $58,000 \mathrm{~km}^{2}$ and including totally 20 districts and counties (cities). The reservoir waters and their fringe areas are generally called the TGR area of the Yangtze River. In fact, TGR is the largest hydroelectric project ever built in China, as well as in the world. The TGR plays acritically important role in economic development and national drinking water safety. In recent years, the researchers investigated the concentrations and distribution of the commonly monitored trace elements in sediments $[2,12]$, agricultural soils $[13,14]$, and aquatic 


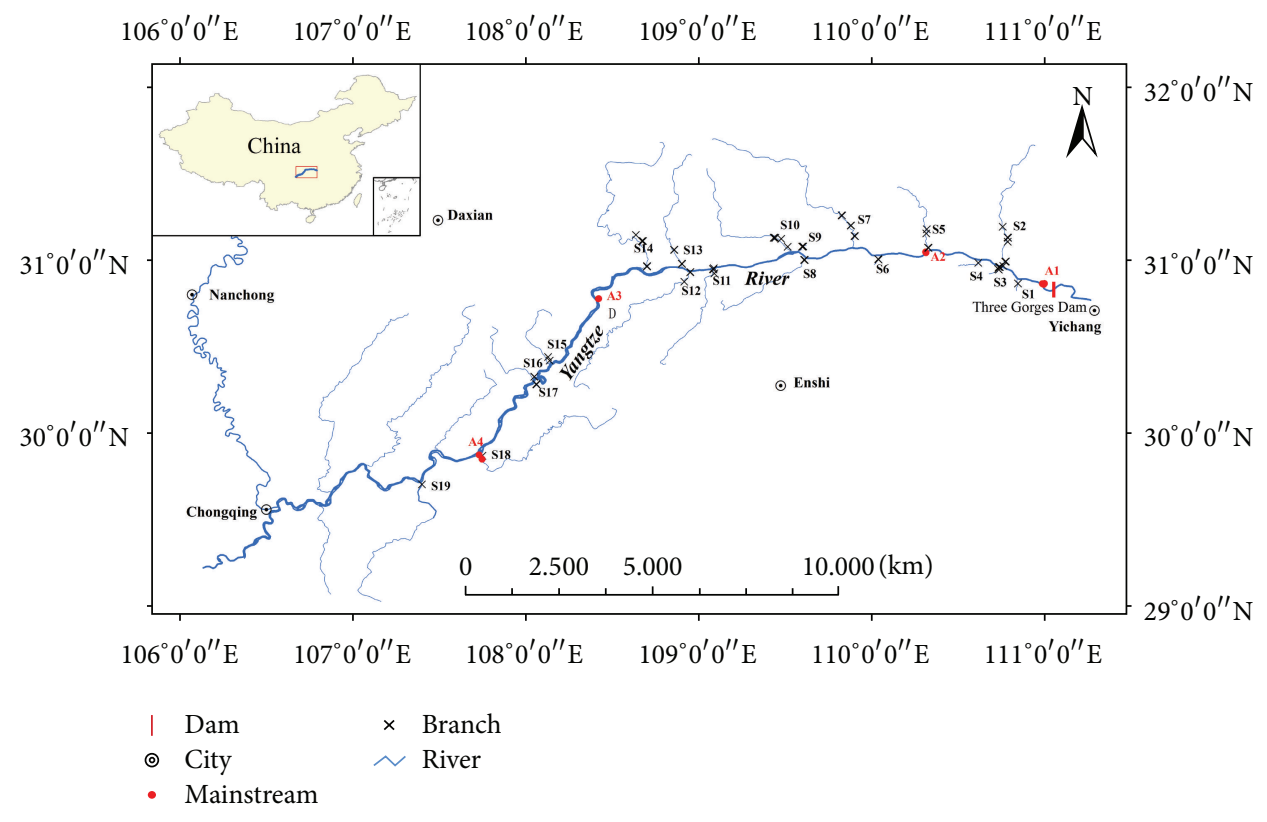

FIGURE 1: Location of sampling sites in TGR, China.

organisms [15] in the region of TGR. However, little concern was arisen to the SMTEs in the aquatic environment. Until now, the concentrations and spatial distribution of SMTEs in sediments of TGR have not been detailedly reported. In fact, as an important category of pollutes in the water environment, a large quantity of industrial and mining activities in TGR may lead to a considerable the SMTEs pollution in this region. The primary objectives of this study were (1) to provide basic information of the concentration levels and spatial distribution of the SMTEs in sediments of TGR after the submergence, (2) to perform pollution assessment of SMTEs in sediments using the Geoaccumulation Index $\left(I_{\text {geo }}\right)$, and (3) to investigate the possible sources of SMTEs in sediments of TGR. It is hoped that this study will not only provide valuable information about SMTEs pollution in TGR after the submergence, but also present a scientific perspective of the environmental effects of the SMTEs in large reservoirs so that further regulatory and environmental attention can be drawn to the issue.

\section{Material and Methods}

2.1. Sampling of Sediments. Seventy-three surface sediment samples were collected from the mainstream and major tributaries in TGR in March 2010 after the submergence period. The sampling sites were described within the zone (Figure 1). Four sampling sites were selected from mainstream (A1 A4) and sixty-nine sediment samples were collected from nineteen tributaries ( $\mathrm{S} 1$ to S19) in TGR. About 2 to 5 sediment samples were collected for each tributary (mainly distributed in up, middle, and down area of tributaries). At each sampling site, sediment samples were taken using a plastic trowel near the middle of the flow of the stream. About $1 \mathrm{~kg}$ of sediment was collected into clean polyethylene bags and treated immediately after returning to the laboratory. The sediment samples were wet sieved through an acid-cleaned $63 \mu \mathrm{m}$ mesh nylon sieve in order to obtain the chemically active material, dried at $40^{\circ} \mathrm{C}(24 \mathrm{~h})$ to constant weight, and ground in an agate mortar in order to ensure sample homogeneity.

2.2. Analytical Methods. All chemical treatments were in the ultraclean laboratory, and all reagents were of high purity grade. Total SMTEs concentrations in sediments were measured using established method [8]. Briefly, a mass of $40 \mathrm{mg}$ of dry sample was weighed and dissolved into $10 \mathrm{~mL}$ Teflon bombs. About $4 \mathrm{~mL}$ concentrated $\mathrm{HNO}_{3}+0.4 \mathrm{~mL}$ concentrated $\mathrm{H}_{2} \mathrm{O}_{2}$ were added to the samples and were left on a hot plate for one day. This step was to remove organic materials from sediment samples. The samples were then taken to dryness at $120^{\circ} \mathrm{C}$. The residue was dissolved in $1.5 \mathrm{~mL} \mathrm{HNO}_{3}+1.5 \mathrm{~mL} \mathrm{HF}$ of sample. After $20 \mathrm{~min}$ ultrasonic treatment, these samples were taken into sealed bomb and were placed in an oven at $190^{\circ} \mathrm{C}$ for $48 \mathrm{~h}$. This procedure resulted in clear solutions for sediments. After evaporation at $120^{\circ} \mathrm{C}$, samples were dissolved in $1 \% \mathrm{HNO}_{3}$ (v:v). SMTEs concentrations of $\mathrm{Li}, \mathrm{B}, \mathrm{Be}, \mathrm{Bi}, \mathrm{V}, \mathrm{Co}, \mathrm{Ga}, \mathrm{Sn}, \mathrm{Sb}$, and Tl were measured by inductively coupled plasma-mass spectrometry (ICP-MS, Perkin Elmer Elan DRC-e). The quality controls for the strong acid digestion method included reagent blanks, duplicate samples, and standard reference materials. The QA/QC results show no sign of contamination in all the analyses. The accuracy of the analytical procedures employed for the analysis of the SMTEs in surface sediments was checked using the certified reference material of China stream sediment (GSD-12, GBW07312), obtaining good agreements with the certified values (Table 1).

2.3. Index of Geoaccumulation $\left(I_{\text {geo }}\right)$. The Geoaccumulation Index $\left(I_{\text {geo }}\right)$ introduced by Müller [16] was also used to assess 
TABLE 1: GSD-12 certified values, analytical values, and recovery.

\begin{tabular}{lccc}
\hline Element & $\begin{array}{c}\text { Analytical value } \\
\left(\mathrm{mg}^{\left.-\mathrm{kg}^{-1}\right)}\right.\end{array}$ & $\begin{array}{c}\text { Certified values } \\
\left(\mathrm{mg} \cdot \mathrm{kg}^{-1}\right)\end{array}$ & Recovery (\%) \\
\hline $\mathrm{Li}$ & 12.98 & 13.0 & 99.8 \\
$\mathrm{Be}$ & 0.63 & 0.9 & 86.7 \\
$\mathrm{Bi}$ & 0.35 & 0.38 & 92.1 \\
$\mathrm{~B}$ & 27.28 & 26 & 104.9 \\
$\mathrm{~V}$ & 103.95 & 107 & 97.1 \\
$\mathrm{Co}$ & 14.97 & 15.3 & 97.8 \\
$\mathrm{Ga}$ & 7.00 & 6.4 & 109.4 \\
$\mathrm{Sn}$ & 1.24 & 1.4 & 88.6 \\
$\mathrm{Sb}$ & 6.39 & 6.3 & 101.4 \\
$\mathrm{Tl}$ & 0.19 & 0.21 & 90.5 \\
\hline
\end{tabular}

TABLE 2: Description of sediment quality.

\begin{tabular}{lcl}
\hline $\begin{array}{l}\text { geo } \\
\text { rank }\end{array}$ & $I_{\text {geo }}$ & Pollution level \\
\hline 6 & $>5$ & Extremely contaminated \\
5 & $4 \sim 5$ & Strongly to extremely strongly contaminated \\
4 & $3 \sim 4$ & Strongly contaminated \\
3 & $2 \sim 3$ & Moderately to strongly contaminated \\
2 & $1 \sim 2$ & Moderately contaminated \\
1 & $0 \sim 1$ & Uncontaminated to moderately contaminated \\
0 & $<0$ & Uncontaminated \\
\hline
\end{tabular}

SMTEs pollution in sediments of TGR. Geoaccumulation Index is expressed as follows:

$$
I_{\text {geo }}=\log _{2}\left(\frac{C_{n}}{1.5 B_{n}}\right),
$$

where $C_{n}$ is the measured concentration of trace metal $(n)$ in the sediment, $B_{n}$ is the geochemical background value [17] of element $n$, and 1.5 is the background matrix correction factor due to lithogenic effects. The Geoaccumulation Index includes seven grades from Class $0\left(I_{\text {geo }} \leq 0\right)$ to Class 6 $\left(I_{\text {geo }}>5\right)$. The Class 6 reflects at least 100 -fold enrichment above the background values. Based on the $I_{\text {geo }}$ data and Muller's Geoaccumulation Indexes, the contamination level with respect to each metal of sediment samples is ranked in Table 2.

\section{Results and Discussion}

3.1. Concentrations of SMTEs. SMTEs concentrations and statistics results in sediments of TGR are summarized in Table 2. SMTEs concentrations in background values and stream sediments in other important rivers of China are also presented in Table 2. As can be seen, the average concentrations of these SMTEs were ranked: $\mathrm{V}>\mathrm{B}>\mathrm{Li}>$ $\mathrm{Ga}>\mathrm{Co}>\mathrm{Sb}>\mathrm{Sn}>\mathrm{Be}>\mathrm{Tl}>\mathrm{Bi}$. In general, the mean concentrations of SMTEs in TGR were slightly higher than those background values in stream sediments [18] and soils in China [19], indicating that the TGR sediments may

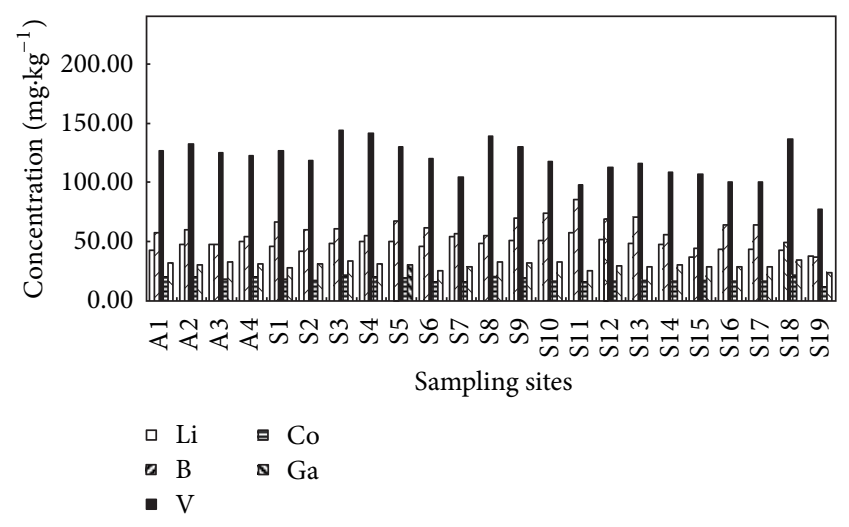

(a)

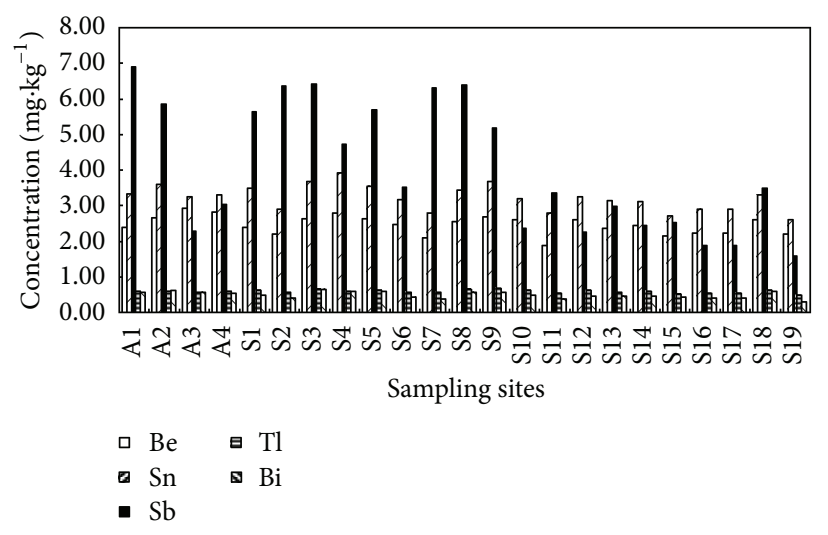

(b)

FIGURE 2: Spatial distribution of SMTEs in sediments from TGR tributaries.

be polluted by these SMTEs from anthropogenic sources. Comparing with those background values in this region, the average concentrations of $\mathrm{Li}, \mathrm{Be}, \mathrm{Bi}, \mathrm{V}, \mathrm{Co}, \mathrm{Ga}, \mathrm{Sn}, \mathrm{Sb}$, and $\mathrm{Tl}$ in TGR sediments were relatively higher than those of background values in Yangtze River, except for B and Sn [20]. Among these SMTEs, the Sb concentration is 5-fold higher than those of background value in Yangtze River, indicating the occurrence of an anthropogenic source of Sb. In fact, the SMTEs concentrations were also those concentrations in other rivers (Yellow River and Pearl River) in China. In addition, higher values of relative standard deviation (RSD > $40 \%$ ) of Sb concentrations in sediments also suggested that the Sb sources were relatively complicated and anthropogenic inputs were possible to be the main source of the SMTEs (Table 3).

3.2. Distribution of SMTEs. Spatial distribution of the SMTEs in surface sediments of TGR is shown in Figure 2. In general, the SMTEs concentrations have an increasing tendency from upstream to downstream for the mainstream of TGR (from A4 to A1), especially for Sb. Among all the sediments, the highest $\mathrm{Sb}$ concentrations were found in the downstream (A1) in TGR. A large amount of anthropogenic activities in TGR area may explain this surprising enrichment of Sb, especially for mining activities and geological condition in 
TABLE 3: Statistics results of SMTEs concentrations in sediments of TGR ( $\left.\mathrm{mg} \cdot \mathrm{kg}^{-1}\right)$.

\begin{tabular}{lccccccccccc}
\hline Statistic & $\mathrm{Li}$ & $\mathrm{Be}$ & $\mathrm{B}$ & $\mathrm{Bi}$ & $\mathrm{V}$ & $\mathrm{Co}$ & $\mathrm{Ga}$ & $\mathrm{Sn}$ & $\mathrm{Sb}$ & $\mathrm{Tl}$ & References \\
\hline Min & 37.30 & 1.89 & 37.31 & 0.30 & 77.47 & 11.30 & 24.24 & 2.60 & 1.59 & 0.48 & This study \\
Max & 54.03 & 2.83 & 73.74 & 0.69 & 143.55 & 21.53 & 34.53 & 3.90 & 6.90 & 0.67 & This study \\
Mean & 47.08 & 2.47 & 59.15 & 0.50 & 119.20 & 17.83 & 30.31 & 3.25 & 4.14 & 0.58 & This study \\
S.D. & 4.88 & 0.26 & 11.41 & 0.10 & 15.86 & 2.27 & 2.81 & 0.36 & 1.76 & 0.04 & This study \\
RSD (\%) & 10.37 & 10.39 & 19.28 & 19.84 & 13.31 & 12.71 & 9.26 & 10.95 & 42.48 & 7.26 & This study \\
Sediments in China & 32 & 2.2 & 48 & 0.39 & 80 & 12 & - & 3.4 & 0.96 & - & {$[18]$} \\
Soils in China & 32 & 2.0 & 48 & 0.37 & 82 & 13 & 17.5 & 2.6 & 1.2 & 0.62 & {$[19]$} \\
Crust & 20 & 2.8 & 10 & 0.17 & 135 & 25 & 15 & 2 & 0.2 & 0.45 & {$[21]$} \\
Yangtze River & 43 & 1.9 & 63 & 0.42 & 97 & 17 & 16 & 3.5 & 0.83 & 0.49 & {$[18]$} \\
Yellow River & 23 & 1.7 & 52 & 0.13 & 60 & 9 & 11 & 2.5 & 0.62 & 0.45 & {$[18]$} \\
Pearl River & 40.1 & - & - & 5.02 & 113 & 16.2 & 13.1 & 1.46 & - & - & {$[20]$} \\
Beijing River & - & - & - & - & 28.56 & 9.64 & 17.25 & 85.61 & 38.98 & - & {$[8]$} \\
\hline
\end{tabular}

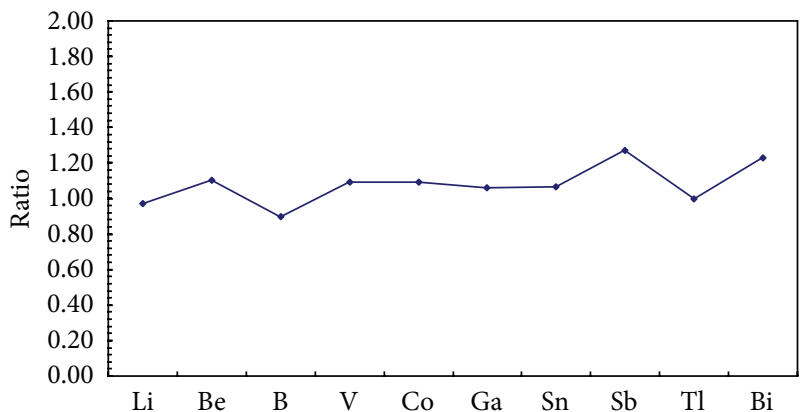

FIGURE 3: SMTEs concentration ratios in sediments between mainstream and tributaries.

upstream of TGR. In fact, the wastewater having the high concentrations $\mathrm{Sb}$ entered into the TGR and the SMTEs in water were absorbed into the suspended particles and eventually deposited into downstream with the water flow.

The mean concentrations ratios of SMTEs between mainstream and tributaries were calculated and showed in Figure 3. In general, SMTEs concentrations in sediments collected from TGR mainstream were slightly higher than those values in tributaries, except for Li, B, and $\mathrm{Tl}$ (Figure 3 ). For tributaries, the concentration of SMTEs had an increasing tendency from upstream to downstream (S19 to S1), except for sampling site S18. In the sampling site S18, the SMTEs concentrations were relatively high among the sampling sites in upstream of TGR, especially for V, Co, Ga, Bi, and Fe. Because these SMTEs are known as the basic elements coming from natural geological sources, the high concentrations of $\mathrm{V}, \mathrm{Co}$, $\mathrm{Ga}, \mathrm{Bi}$, and $\mathrm{Fe}$ in $\mathrm{S} 18$ may be attributed into the relatively high environmental background in this region. Our results also showed that higher concentrations of Sb and Sn were also frequently detected in the downstream of TGR (Figure 3).

3.3. Pollution Assessment. Based on the $I_{\text {geo }}$ data and Geoaccumulation Indexes, the results of the calculated $I_{\text {geo }}$ values with respect to SMTEs are presented in Table 4. In general, the results of the average $I_{\text {geo }}$ values are 0.65 for $\mathrm{Li},-0.78$ for Be, 1.99 for $\mathrm{B},-0.78$ for $\mathrm{V},-1.09$ for $\mathrm{Co}, 0.41$ for $\mathrm{Ga}$, 0.09 for $\mathrm{Sn}, 3.60$ for $\mathrm{Sb},-0.21$ for $\mathrm{Tl}, 0.92$ for $\mathrm{Bi}$, and -1.29 for Fe, respectively. The order of average $I_{\text {geo }}$ values in TGR sediments was $\mathrm{Sb}>\mathrm{B}>\mathrm{Bi}>\mathrm{Li}>\mathrm{Ga}>\mathrm{Sn}>$ $\mathrm{Tl}>\mathrm{Be}>\mathrm{V}>\mathrm{Co}>\mathrm{Fe}$. In general, the average $I_{\text {geo }}$ values of $\mathrm{Tl}, \mathrm{Be}, \mathrm{V}, \mathrm{Co}$, and $\mathrm{Fe}$ are less than zero $\left(I_{\text {geo }} \leq 0\right)$, indicating that TGR sediments are unpolluted with respect to these five SMTEs. However, the average $I_{\text {geo }}$ of Sb had the highest value and was ranked as "strongly contaminated" level (Class 4), indicating that TGR had significant accumulation of $\mathrm{Sb}$ apparently from anthropogenic sources. In fact, $\mathrm{Sb}$ was ranked as "extremely contaminated" in several sampling sites, including sampling sites S1, S2, S3, S5, S7, S8, and S9. In addition, $\mathrm{B}$ was classified as Class 2 which indicated the sediment quality as "moderately contaminated." $\mathrm{Bi}, \mathrm{Li}, \mathrm{Ga}$, and Sn were ranked in Class 1, standing for "uncontaminated to moderately contaminated" level in TGR sediments.

3.4. Origins of the SMTEs in Sediments. TGR receives a variety of inputs of heavy metals from nature and anthropogenic natural sources according to the high metal concentrations in sediments. In a further attempt to assess the sources responsible for the observed pollution levels, Correlation Analysis and Principal Component Analysis (PCA) were applied to data set of total concentrations of surface sediments in TGR. Correlation Analysis results (Table 5) indicated that Be, V, $\mathrm{Co}, \mathrm{Ga}, \mathrm{Sn}$, and Fe have significant correlations with each other, suggesting that they had the same source. However, nonsignificant correlations of $\mathrm{Sb}$ with other ten elements ( $\mathrm{Li}$, $\mathrm{Be}, \mathrm{B}, \mathrm{V}, \mathrm{Co}, \mathrm{Ga}, \mathrm{Sn}, \mathrm{Tl}, \mathrm{Bi}$, and $\mathrm{Fe}$ ) may be possibly due to different sources and have external inputs in sediments. In addition, the correlation results also showed that $\mathrm{Li}$, $\mathrm{B}$, and $\mathrm{Tl}$ were also positively correlated with each other, demonstrating a common source in sediments.

The method of the PCA is a multivariate statistical technique that can be employed to reduce the dimensionality of a data set while attempting to preserve the relationships present in the original data and was used to assess trace metal behavior in the aquatic system $[8,22,23]$. The rotated component matrixes of the PCA of SMTEs are presented in Table 6. The results of the PCA indicated that Li, Be, B, V, Co, 
TABLE 4: $I_{\text {geo }}$ values of SMTEs in sediments of Three Gorges Reservoir.

\begin{tabular}{|c|c|c|c|c|c|c|c|c|c|c|c|}
\hline Station & $\mathrm{Li}$ & $\mathrm{Be}$ & B & $\mathrm{V}$ & Co & $\mathrm{Ga}$ & Sn & $\mathrm{Sb}$ & $\mathrm{Tl}$ & $\mathrm{Bi}$ & $\mathrm{Fe}$ \\
\hline S1 & 0.62 & -0.81 & 2.16 & -0.68 & -1.05 & 0.32 & 0.22 & 4.23 & -0.16 & 0.93 & -1.33 \\
\hline $\mathrm{S} 2$ & 0.49 & -0.93 & 2.00 & -0.78 & -1.15 & 0.47 & -0.04 & 4.41 & -0.23 & 0.69 & -1.24 \\
\hline S3 & 0.70 & -0.67 & 2.02 & -0.50 & -0.80 & 0.58 & 0.29 & 4.42 & -0.08 & 1.34 & -0.92 \\
\hline S4 & 0.73 & -0.58 & 1.87 & -0.52 & -0.92 & 0.47 & 0.38 & 3.98 & -0.21 & 1.23 & -1.07 \\
\hline S5 & 0.75 & -0.68 & 2.18 & -0.64 & -0.96 & 0.45 & 0.24 & 4.24 & -0.14 & 1.18 & -1.32 \\
\hline S6 & 0.61 & -0.76 & 2.04 & -0.75 & -1.24 & 0.17 & 0.08 & 3.55 & -0.26 & 0.73 & -1.34 \\
\hline S7 & 0.85 & -1.01 & 1.91 & -0.96 & -1.26 & 0.35 & -0.10 & 4.40 & -0.23 & 0.59 & -1.34 \\
\hline S8 & 0.69 & -0.73 & 1.87 & -0.55 & -0.89 & 0.55 & 0.19 & 4.41 & -0.07 & 1.11 & -1.02 \\
\hline S9 & 0.77 & -0.64 & 2.21 & -0.64 & -0.97 & 0.52 & 0.29 & 4.11 & 0.00 & 1.18 & -1.65 \\
\hline S10 & 0.75 & -0.69 & 2.30 & -0.79 & -1.19 & 0.54 & 0.09 & 2.97 & -0.12 & 0.93 & -1.38 \\
\hline S11 & 0.94 & -1.15 & 2.51 & -1.06 & -1.26 & 0.18 & -0.10 & 3.48 & -0.30 & 0.60 & -1.44 \\
\hline $\mathrm{S} 12$ & 0.78 & -0.69 & 2.20 & -0.85 & -1.21 & 0.38 & 0.11 & 2.90 & -0.13 & 0.84 & -1.28 \\
\hline $\mathrm{S} 13$ & 0.68 & -0.84 & 2.24 & -0.80 & -1.12 & 0.35 & 0.06 & 3.31 & -0.23 & 0.83 & -1.35 \\
\hline S14 & 0.67 & -0.78 & 1.91 & -0.90 & -1.18 & 0.44 & 0.05 & 3.03 & -0.20 & 0.81 & -1.30 \\
\hline S15 & 0.31 & -0.97 & 1.55 & -0.92 & -1.10 & 0.34 & -0.14 & 3.07 & -0.38 & 0.71 & -1.25 \\
\hline S16 & 0.54 & -0.91 & 2.10 & -1.01 & -1.19 & 0.36 & -0.05 & 2.65 & -0.31 & 0.68 & -1.38 \\
\hline S17 & 0.54 & -0.91 & 2.10 & -1.01 & -1.19 & 0.36 & -0.05 & 2.65 & -0.31 & 0.68 & -1.38 \\
\hline S18 & 0.51 & -0.69 & 1.72 & -0.57 & -0.82 & 0.62 & 0.14 & 3.55 & -0.16 & 1.20 & -0.93 \\
\hline S19 & 0.34 & -0.93 & 1.31 & -1.39 & -1.73 & 0.11 & -0.21 & 2.40 & -0.50 & 0.22 & -1.78 \\
\hline $\mathrm{A} 1$ & 0.52 & -0.81 & 1.93 & -0.68 & -0.94 & 0.49 & 0.15 & 4.52 & -0.19 & 1.12 & -1.59 \\
\hline A2 & 0.66 & -0.66 & 2.00 & -0.61 & -0.95 & 0.43 & 0.26 & 4.29 & -0.20 & 1.30 & -1.01 \\
\hline A3 & 0.66 & -0.52 & 1.67 & -0.70 & -1.06 & 0.55 & 0.12 & 2.92 & -0.24 & 1.15 & -1.19 \\
\hline $\mathrm{A} 4$ & 0.75 & -0.57 & 1.85 & -0.72 & -0.95 & 0.48 & 0.14 & 3.34 & -0.20 & 1.09 & -1.09 \\
\hline Average & 0.65 & -0.78 & 1.99 & -0.78 & -1.09 & 0.41 & 0.09 & 3.60 & -0.21 & 0.92 & -1.29 \\
\hline
\end{tabular}

TABLE 5: Correlation coefficients of SMTEs in TGR sediments.

\begin{tabular}{|c|c|c|c|c|c|c|c|c|c|c|c|}
\hline & $\mathrm{Li}$ & $\mathrm{Be}$ & $\mathrm{B}$ & $\mathrm{V}$ & $\mathrm{Co}$ & $\mathrm{Ga}$ & Sn & $\mathrm{Sb}$ & $\mathrm{Tl}$ & $\mathrm{Bi}$ & $\mathrm{Fe}$ \\
\hline $\mathrm{Li}$ & 1.000 & $0.278^{*}$ & $0.502^{* *}$ & 0.195 & 0.106 & 0.056 & $0.325^{* *}$ & -0.046 & $0.555^{* *}$ & 0.173 & 0.100 \\
\hline $\mathrm{Be}$ & & 1.000 & 0.016 & $0.736^{* *}$ & $0.693^{* *}$ & $0.493^{* *}$ & $0.859^{* *}$ & -0.152 & $0.629^{* *}$ & $0.792^{* *}$ & $0.423^{* *}$ \\
\hline B & & & 1.000 & 0.151 & 0.030 & -0.120 & 0.115 & -0.078 & $0.287^{*}$ & 0.024 & 0.006 \\
\hline V & & & & 1.000 & $0.921^{* *}$ & $0.578^{* *}$ & $0.828^{* *}$ & $0.282^{*}$ & $0.737^{* *}$ & $0.837^{* *}$ & $0.527^{* *}$ \\
\hline Co & & & & & 1.000 & $0.537^{* *}$ & $0.806^{* *}$ & $0.291^{*}$ & $0.613^{* *}$ & $0.877^{* *}$ & $0.509^{* *}$ \\
\hline $\mathrm{Ga}$ & & & & & & 1.000 & $0.475^{* *}$ & 0.198 & $0.608^{* *}$ & $0.525^{* *}$ & $0.289^{*}$ \\
\hline Sn & & & & & & & 1.000 & 0.071 & $0.689^{* *}$ & $0.865^{* *}$ & $0.444^{* *}$ \\
\hline $\mathrm{Sb}$ & & & & & & & & 1.000 & 0.168 & 0.151 & 0.133 \\
\hline $\mathrm{Tl}$ & & & & & & & & & 1.000 & $0.575^{* *}$ & $0.292^{*}$ \\
\hline $\mathrm{Bi}$ & & & & & & & & & & 1.000 & $0.500^{* *}$ \\
\hline $\mathrm{Fe}$ & & & & & & & & & & & 1.000 \\
\hline
\end{tabular}

${ }^{*}$ Correlation is significant at the 0.05 level (2-tailed).

${ }^{* *}$ Correlation is significant at the 0.01 level (2-tailed).

$\mathrm{Ga}, \mathrm{Sn}, \mathrm{Sb}, \mathrm{Tl}, \mathrm{Bi}$, and Fe concentrations could be reduced to three components (PC1, PC2, and PC3), which accounted for $76.83 \%$ of the total variance for all the data.

Firstly, the high loading of Be, V, Co, Ga, Sn, Tl, Bi, and $\mathrm{Fe}$ explained about $49.23 \%$ of the total variance. The concentrations of these elements were close to the background. Furthermore, Fe, Be, and V are generally named as the elements from the natural geological environment and $\mathrm{Co}, \mathrm{Ga}, \mathrm{Sn}, \mathrm{Tl}$, and $\mathrm{Bi}$ have a good correlation with $\mathrm{Fe}, \mathrm{Be}$, and V. Consequently, this factor can be identified as "natural factor." The second component (PC2), which explains 16.71\% of the total variance, appears to represent an "anthropogenic factor," as it is strongly loaded with the elements of $\mathrm{Li}$ and B. In fact, TGR area is located in the Chongqing and Hubei Province and there is a high density of population. The anthropogenic activities may have an obvious impact on these two elements ( $\mathrm{B}$ and $\mathrm{Li}$ ) in sediments in TGR area. $\mathrm{B}$ is a common element in detergent and the detergent is frequently used in daily life such as washing powder. Therefore, the domestic wastewater including detergents may be one of 
TABLE 6: Component pattern matrix for varimax rotated PCA analysis for SMTEs.

\begin{tabular}{lccc}
\hline \multirow{2}{*}{ Elements } & \multicolumn{3}{c}{ Component } \\
& PC1 & PC2 & PC3 \\
\hline $\mathrm{Li}$ & 0.149 & $\mathbf{0 . 8 6 3}$ & -0.075 \\
$\mathrm{Be}$ & $\mathbf{0 . 8 7 6}$ & 0.123 & -0.333 \\
$\mathrm{~B}$ & -0.062 & $\mathbf{0 . 8 4 3}$ & -0.004 \\
$\mathrm{~V}$ & $\mathbf{0 . 9 1 3}$ & 0.171 & 0.203 \\
$\mathrm{Co}$ & $\mathbf{0 . 9 0 9}$ & 0.030 & 0.201 \\
$\mathrm{Ga}$ & $\mathbf{0 . 6 6 9}$ & -0.050 & 0.222 \\
$\mathrm{Sn}$ & $\mathbf{0 . 9 0 3}$ & 0.217 & -0.094 \\
$\mathrm{Sb}$ & 0.128 & -0.037 & $\mathbf{0 . 9 5 6}$ \\
$\mathrm{Tl}$ & $\mathbf{0 . 6 9 2}$ & 0.533 & 0.147 \\
$\mathrm{Bi}$ & $\mathbf{0 . 9 2 5}$ & 0.044 & 0.006 \\
$\mathrm{Fe}$ & $\mathbf{0 . 5 9 0}$ & -0.037 & 0.079 \\
Explained variance in \% & 49.23 & 16.71 & 10.89 \\
\hline
\end{tabular}

the main sources of $\mathrm{B}$ and $\mathrm{Li}$ in the sediments. In fact, the high concentration of $B$ is a distinct marker of household waste water. On one hand, the household wastewater including B is discharged directly into the river in rural areas. On the other hand, B in the water is also difficult to remove through simple water treatment procedures. Thirdly, the results of the PCA displayed that $\mathrm{Sb}$ has less association with other SMTEs and it is an independent component (PC3), indicating that $\mathrm{Sb}$ has another kind of anthropogenic source. Usually, Sb is a byproduct in mining activities. In this region, mining activities and metal refining activities in the upper region of TGR area may be responsible for these excess Sb.

\section{Conclusions}

Our investigation of SMTEs, such as $\mathrm{Li}, \mathrm{Be}, \mathrm{B}, \mathrm{V}, \mathrm{Co}, \mathrm{Ga}, \mathrm{Sn}$, $\mathrm{Sb}, \mathrm{Tl}$, and $\mathrm{Bi}$ in sediment samples in TGR and its tributaries, observes that the mean concentrations of Sb in sediments of TGR were obviously higher than those in stream sediments of China and previous results, indicating the occurrence of an anthropogenic source of the SMTEs. The assessment by Geoaccumulation Index indicated that $\mathrm{Tl}, \mathrm{Be}, \mathrm{V}, \mathrm{Co}$, and Fe were at the unpolluted level; $\mathrm{Bi}, \mathrm{Li}, \mathrm{Ga}$, and $\mathrm{Sn}$ were at the "uncontaminated to moderately contaminated" level, $\mathrm{B}$ was at the "moderately contaminated" level, and Sb was at the "strongly contaminated" level. The pollution level of the SMTEs is $\mathrm{Sb}>\mathrm{B}>\mathrm{Bi}>\mathrm{Li}>\mathrm{Ga}>\mathrm{Sn}>$ $\mathrm{Tl}>\mathrm{Be}>\mathrm{V}>\mathrm{Co}>\mathrm{Fe}$. The results of Correlation Analysis and PCA indicated that B and Li were positively correlated with each other, demonstrating a common source in sediments. In addition, our results indicated that the sediments in TGR have been severely contaminated by $\mathrm{Sb}$ and it has different anthropogenic sources among SMTEs. These results will provide fundamental pollution information of the SMTEs in TGR. Further research is required to investigate the behaviors and fates of SMTEs in river sediments and evaluate the bioavailability, toxicity, and ecological risks in water environment.

\section{Conflict of Interests}

The authors declare no competing financial interests regarding the publication of this paper.

\section{Acknowledgments}

This work was jointly supported by the Major Science and Technology Program for Water Pollution Control and Treatment (Grant no. 2012ZX07104-001), the Open Research Fund of State Key Laboratory of Simulation and Regulation of Water Cycle in River Basin, China Institute of Water Resources and Hydropower Research (Grant nos. 2014QN02, 2014RC08), and China Postdoctoral Science Foundation (Grant no. 2013M530668).

\section{References}

[1] U. Förstner, Contaminated Sediments: Lectures on Environmental Aspects of Particle-Associated Chemicals in Aquatic Systems, Springer, Berlin, Germany, 1989.

[2] Z. Yang, Y. Wang, Z. Shen, J. Niu, and Z. Tang, "Distribution and speciation of heavy metals in sediments from the mainstream, tributaries, and lakes of the Yangtze River catchment of Wuhan, China," Journal of Hazardous Materials, vol. 166, no. 2-3, pp. 1186-1194, 2009.

[3] Y. Yi, Z. Yang, and S. Zhang, "Ecological risk assessment of heavy metals in sediment and human health risk assessment of heavy metals in fishes in the middle and lower reaches of the Yangtze River basin," Environmental Pollution, vol. 159, no. 10, pp. 2575-2585, 2011.

[4] F. Wu, Z. Fu, B. Liu et al., "Health risk associated with dietary coexposure to high levels of antimony and arsenic in the world's largest antimony mine area," Science of the Total Environment, vol. 409, no. 18, pp. 3344-3351, 2011.

[5] L. Laforte, A. Tessier, C. Gobeil, and R. Carignan, "Thallium diagenesis in lacustrine sediments," Geochimica et Cosmochimica Acta, vol. 69, no. 22, pp. 5295-5306, 2005.

[6] B. Gao, K. Sun, M. Z. Ren et al., "Ecological risk assessment of thallium pollution in the surface sediment of Three Gorge Reservoir," Ecology and Environment, vol. 17, no. 2, pp. 528-532, 2008 (Chinese).

[7] L. Duan, J. Song, Y. Xu, X. Li, and Y. Zhang, "The distribution, enrichment and source of potential harmful elements in surface sediments of Bohai Bay, North China," Journal of Hazardous Materials, vol. 183, no. 1-3, pp. 155-164, 2010.

[8] B. Gao, J. Lu, H. D. Zhou, S. H. Yin, and H. Hao, "The distribution, accumulation and potential source of seldom monitored trace elements in sediments of Beijiang River, South China," Water Science and Technology, vol. 65, no. 12, pp. 21182124, 2012.

[9] D. C. Crans, J. J. Smee, E. Gaidamauskas, and L. Q. Yang, "The chemistry and biochemistry of vanadium and the biological activities exerted by vanadium compounds," Chemical Reviews, vol. 104, no. 2, pp. 849-902, 2004.

[10] M. Filella, N. Belzile, and Y. Chen, "Antimony in the environment: a review focused on natural waters: I. Occurence," EarthScience Reviews, vol. 57, no. 1-2, pp. 125-176, 2002.

[11] E. Grahn, S. Karlsson, and A. Düker, "Sediment reference concentrations of seldom monitored trace elements (Ag, Be, In, 
$\mathrm{Ga}, \mathrm{Sb}, \mathrm{Tl}$ ) in four Swedish boreal lakes-comparison with commonly monitored elements," Science of the Total Environment, vol. 367, no. 2-3, pp. 778-790, 2006.

[12] Y. Song, J. Ji, C. Mao et al., "Heavy metal contamination in suspended solids of Changjiang River-environmental implications," Geoderma, vol. 159, no. 3-4, pp. 286-295, 2010.

[13] C. Ye, S. Li, Y. Zhang, and Q. Zhang, "Assessing soil heavy metal pollution in the water-level-fluctuation zone of the Three Gorges Reservoir, China," Journal of Hazardous Materials, vol. 191, no. 1-3, pp. 366-372, 2011.

[14] Y. Liu, T. Xiao, Z. Ning, H. Li, J. Tang, and G. Zhou, "High cadmium concentration in soil in the Three Gorges region: geogenic source and potential bioavailability," Applied Geochemistry, vol. 37, pp. 149-156, 2013.

[15] Y. Yu, C. Y. Wang, H. D. Zhou, B. Gao, and G. F. Zhao, "Pollution characteristics and health risk assessment of heavy metals in carp (Cyprinus carpio) from the Three Gorges Reservoir after 175 m impoundment," Acta Scientiae Circumstantiae, vol. 33, no. 7, pp. 2013-2019, 2013 (Chinese).

[16] G. Müller, "Schwermetalle in den sedimenten des RheinsVeränderungen seitt 1971," Umschan, vol. 79, pp. 778-783, 1979.

[17] S. R. Taylor and S. M. McLennan, "The chemical composition evolution of the continental crust," Reviews of Geophysics, vol. 33, no. 2, pp. 241-265, 1995.

[18] Q. H. Chi and M. C. Yan, Handbook of Elemental Abundance for Applied Geochemistry, Geological Publishing House, Beijing, China, 2007.

[19] CNEMC (China National Environmental Monitoring Centre), The Background Values of Chinese Soils, Environmental Science Press of China, Beijing, China, 1990, (Chinese).

[20] C. Zhang and L. Wang, "Multi-element geochemistry of sediments from the Pearl River system, China," Applied Geochemistry, vol. 16, no. 9-10, pp. 1251-1259, 2001.

[21] S. R. Taylor, "Abundance of chemical elements in the continental crust: a new table," Geochimica et Cosmochimica Acta, vol. 28, no. 8, pp. 1273-1285, 1964.

[22] E. G. Farmaki, N. S. Thomaidis, I. N. Pasias, C. Baulard, L. Papaharisis, and C. E. Efstathiou, "Environmental impact of intensive aquaculture: investigation on the accumulation of metals and nutrients in marine sediments of Greece," Science of The Total Environment, vol. 485-486, pp. 554-562, 2014.

[23] J. S. Khim and S. Hong, "Assessment of trace pollutants in Korean coastal sediments using the triad approach: a review," Science of the Total Environment, vol. 470-471, pp. 1450-1462, 2014. 

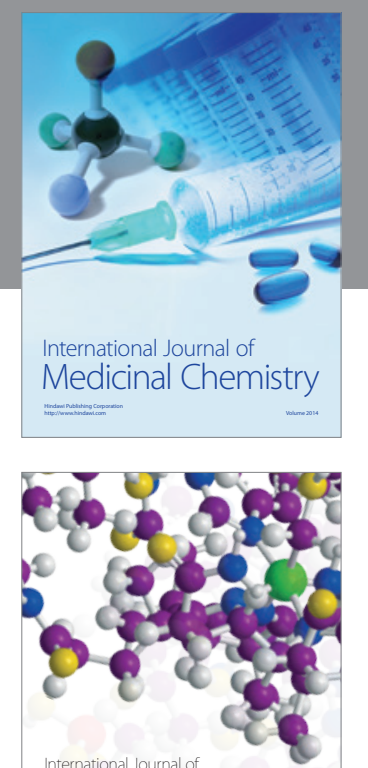

\section{Carbohydrate} Chemistry

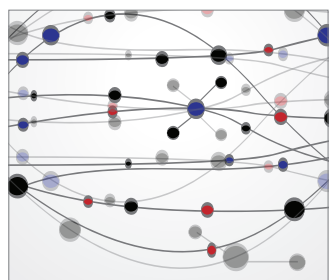

The Scientific World Journal
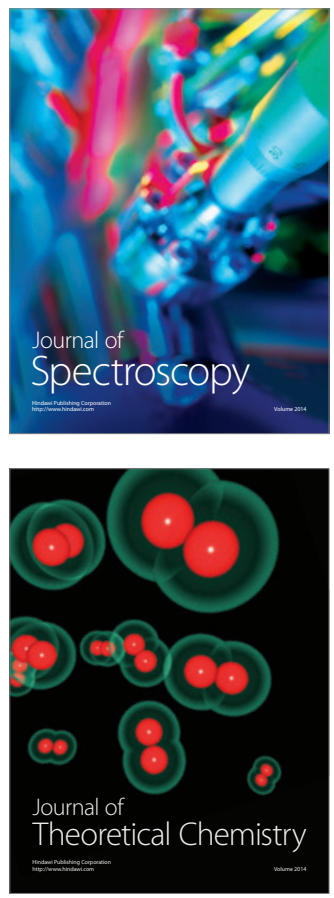
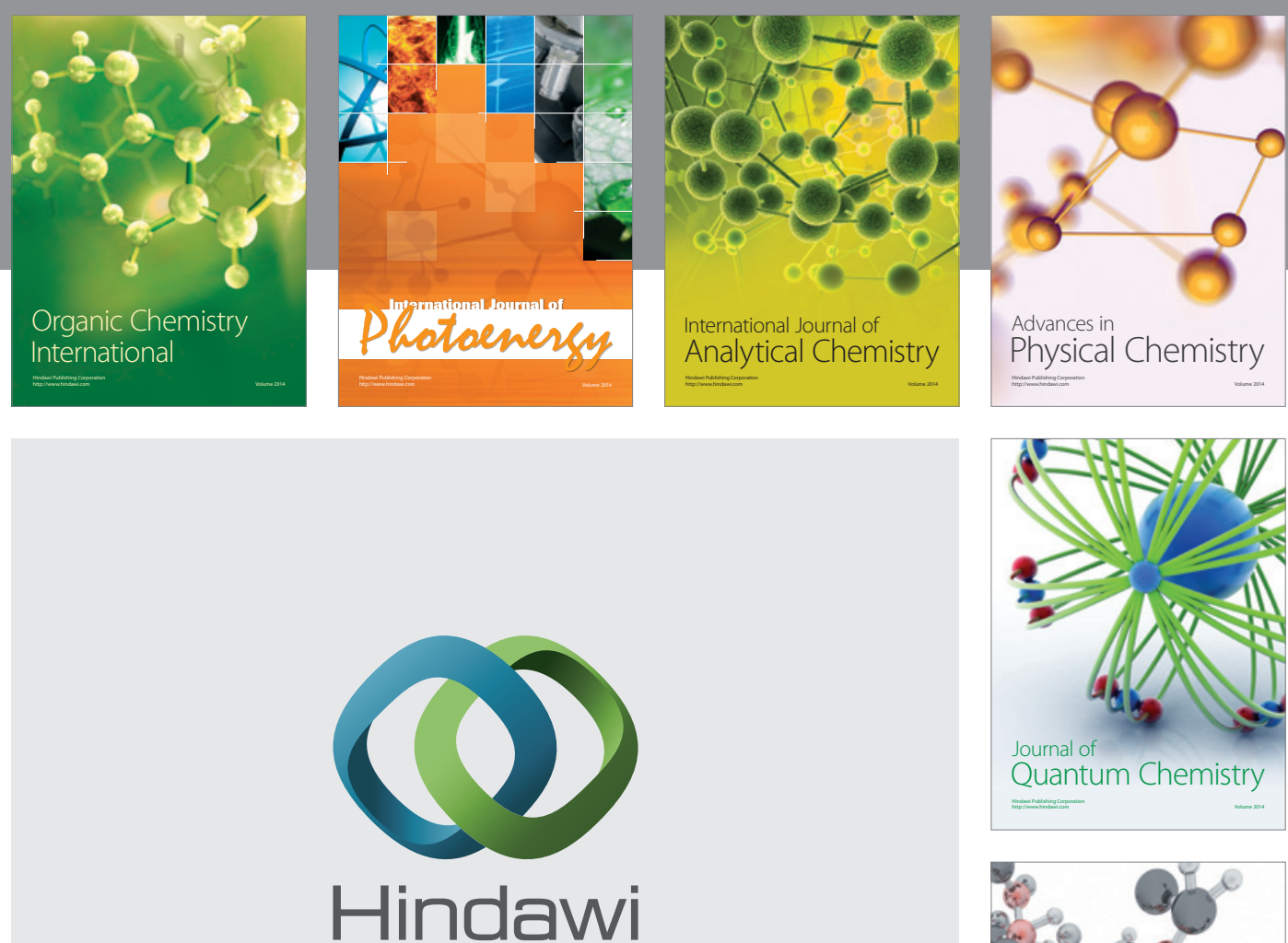

Submit your manuscripts at

http://www.hindawi.com

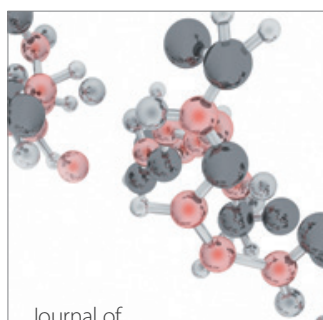

Analytical Methods

in Chemistry

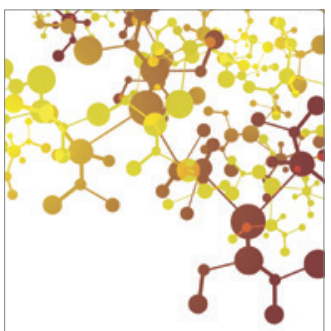

Journal of

Applied Chemistry

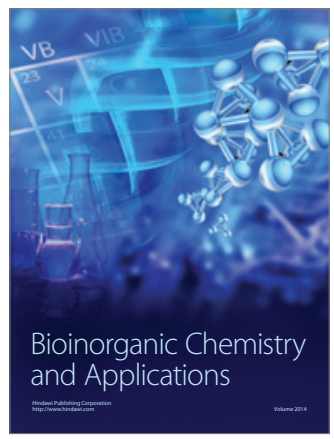

Inorganic Chemistry
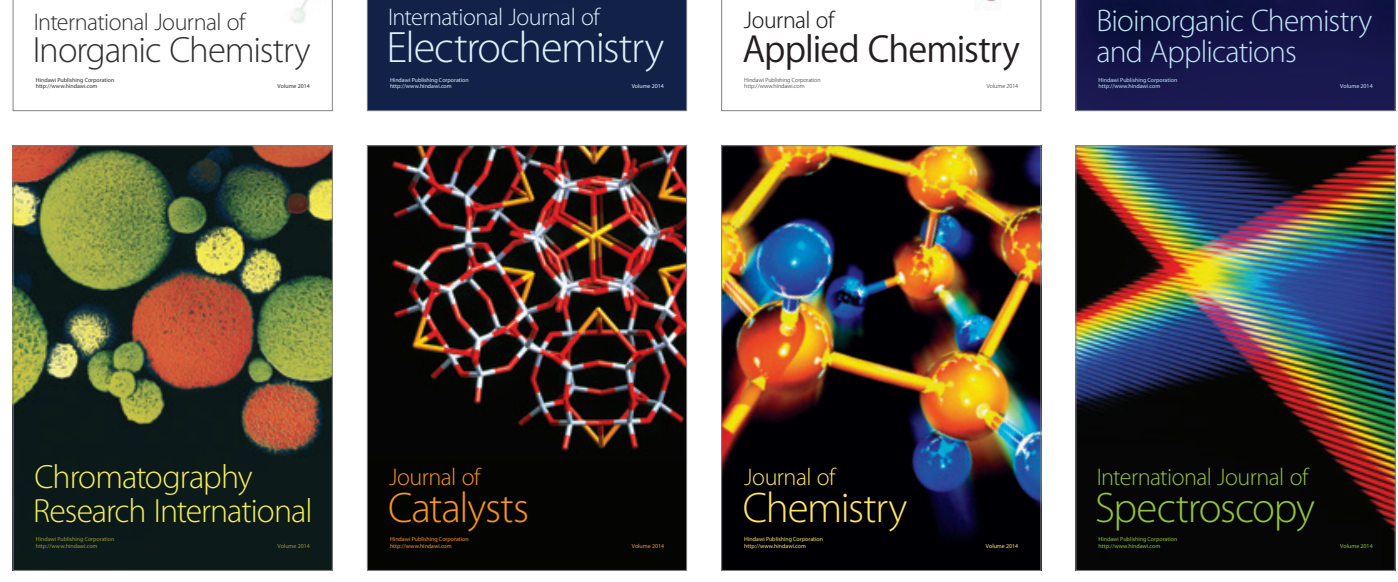